\title{
What Are the Stages of the Creative Process? What Visual Art Students Are Saying.
}

\author{
Marion Botella*, Franck Zenasni and Todd Lubart \\ Laboratoire Adaptations Travail-Individu, Université Paris Descartes, Paris, France
}

Within the literature on creativity in the arts, some authors have focused on the description of the artistic process (Patrick, 1937; Getzels and Csikszentmihalyi, 1976; Mace and Ward, 2002; Yokochi and Okada, 2005) whereas others have focused on the creative process (Wallas, 1926; Osborn, 1953/1963; Runco and Dow, 1999; Howard et al., 2008). These two types of processes may be, however, somewhat distinct from each other because the creative process is not always dedicated to artistic creation, and productive work in the arts may not always involve creativity, in terms of specifically original thinking. Our goal is to identify the specific nature of the artistic creative process, to determine what are the basic stages of this kind of process. This description can then be integrated in a Creative process Report Diary (CRD; Botella et al., 2017) which allows

OPEN ACCESS self-observations in situ when participants are creating.

Keywords: creative process, stages, visual art students, interviews, Creative process Report Diary

\section{FROM THE EXISTING CREATIVE AND ARTISTIC PROCESSES TO THE ARTISTIC CREATIVE PROCESS}

The creative process is defined as a succession of thoughts and actions leading to original and appropriate productions (Lubart, 2001; Lubart et al., 2015). The creative process may be described at two levels: a macro level, featuring the stages of the creative process, and a micro level, which explains the mechanisms underlying the creative process, e.g., divergent thinking or convergent thinking (Botella et al., 2016). Although the works carried out on micro-processes tend to agree on a set of mechanisms that can be involved in the creative process, work focusing on macroprocesses have not achieved consensus regarding the nature or the number of stages involved in the creative process. Table 1 shows some of the different models that can be found in the scientific literature, with overlaps or divisions between some stages of the models. In this paper, we treat microprocesses as contents of a more global, macro-level process, which make it possible to describe the construction of a work of art from the beginning (i.e., the wish to create) to the end (exhibiting that work). Moreover, the process can be examined in a psychological and individual or in a sociocultural perspective (Glǎveanu, 2010; Burnard, 2012). In the present study situated in the visual art field, we will consider the artistic creative process as an individual phenomenon.

Art is often considered to be an archetypal domain of creativity research (Schlewitt-Haynes et al., 2002; Stanko-Kaczmarek, 2012), complimented by research on scientific, musical, design-oriented, and literary creativity (Glaveanu et al., 2013). Even if some overlap can be observed between different creative fields, each field has its own specificities (Botella and Lubart, 2015). The purpose of this section is to merge some existing models of the creative process and artistic process to examine what the artistic creative process could be. Obviously, this section cannot be exhaustive but offers a first consideration of the numerous important stages of the artistic creative process. 
The process starts by an orientation, in which the individual identifies the problem that must be solved (Osborn, 1953/1963), called also a stage of problem selection (Busse and Mansfield, 1980) or a sensitivity to problems (Guilford, 1956). Problem definition involves producing as many questions as possible. For Runco and Dow (1999), problem-finding refers to a process of "sensing gaps" (Torrance, 1962) - that is, detecting elements that are lacking. In the same vein, Bruford (2015) proposed a stage of differentiation consisting of retaining information that leads to producing something different, involving interpretative and expressive musical differences. Additionally, Mumford et al. (1994) suggested making a distinction between discovering a problem (i.e., rejecting problems that are untrue, incorrect, or incomplete; Getzels and Csikszentmihalyi, 1976; Arlin, 1986), posing the problem (i.e., finding a correct formulation), and constructing a problem (i.e., describing the problem). In the artistic field, Fürst et al. (2012) proposed a model of art production that includes a goal of creation.

Then, there is preparation, the first stage described in the early macroprocess model by Wallas (1926). Carson (1999) explained that, in this stage, the individual defines the problem (or understands it; Treffinger, 1995) and gathers information in order to solve it. Based on a series of interviews with novelists, Doyle (1998) argued that the creative process begins with an incident, when an individual discovers an idea. In the artistic process literature, Mace and Ward (2002) proposed a four-stage model based on interviews with professional artists. For them, the artistic process begins with the design of an artistic work. Hence, work is initiated by a more-or-less vague idea or impression. Recently, based also on a series of interviews with professional artists, Botella et al. (2013) identified six stages in the creative process in art, starting by an idea or a "vision" in which an image, a sight, a sound resonates with the artist.

Before the second main stage described by Wallas (1926), some authors added complementary stages after preparation. Based on a previous review of the literature, Botella et al. (2011) propose a stage of concentration ("I am concentrating on the work I have to do") in which it is possible to focus the creator's attention on those solutions deemed to be adequate, and to reject the other solutions (Carson, 1999). Osborn (1953/1963) added analysis, when the creator takes a step back to identify the relations between ideas and the importance of each idea; and ideation, when the individual develops alternative ideas. Busse and Mansfield (1980) indicated also a stage requiring making an effort in order to solve the problem.

Then, according to Wallas (1926) and many other authors, incubation occurs (Osborn, 1953/1963; Shaw, 1989, 1994; Runco, 1997; Runco and Dow, 1999; Botella et al., 2011). This is a time of solitude and relaxation, where idea associations take place at a subconscious level (Carson, 1999). Recently, SadlerSmith (2016) reintegrated a fifth stage in the Wallas' model: intimation occurs between incubation and insight. Intimation is described as an "association-train" in a fringe conscious level, between conscious and unconscious levels (p. 346). Cropley and Cropley (2012) revisited as well Wallas's work and split the stage of incubation into activation and generation. The process once again becomes conscious in the stage of ideation, with the generation of further ideas, which are not necessarily judged or assessed. The individual then experiences an illumination or insight (Eureka!) with the emergence of an idea, an image or a solution (Wallas, 1926; Carson, 1999). Boden (2004) noted that illumination or insight needs previous thought-processes.

Idea generation can take place in various ways according to the different models. Busse and Mansfield (1980) described a stage in which the creator sets the constraints related to the solution of the problem and, then, another stage involving the transformation of these constraints or adaptation of the constraints that are not suitable. For Doyle (1998), there is some form of navigation between various knowledge domains, which makes it possible to assess the relevance of this idea. Based on Dewey (1934), Bruford (2015) proposed a selection stage in which the creator choses one option among several, requiring agency and control abilities. In the field of art, Mace and Ward (2002) named this step idea development in which the artist structures, completes, and restructures the idea. Botella et al. (2013), through interviews with professional artists identified a stage of documentation and reflection during which artists gather more information about the materials and technologies required in order to turn their vision into reality. The last stage described by Wallas (1926) is verification (Busse and Mansfield, 1980). New ideas are tested and verified, leading to the elaboration of a solution and to its production (Carson, 1999). More precisely, Osborn (1953/1963) proposed two distinct phases of synthesis, which consists of gathering ideas together and distinguishing relations between them.

Gruber (1989) argued that the four-stage model is incomplete. For Russ (1993), there lacks a stage of application, or deployment of the creative production. Treffinger (1995) added effectively a stage of idea production, leading to action by planning. This work corresponds to the development and implementation of ideas through a search for solutions (evaluation, selection, and redefinition), and then the acceptance of this solution (promoting an idea, looking for its strengths and drawbacks). This last stage makes it possible to materialize the ideas that have been found and to solve the problem. In this vein, in the field of art, Mace and Ward (2002) described the realization of an idea, during which the artist transforms that idea into a physical entity. Botella et al. (2011) also added stages of planning ("I am planning my work"), and production ("I am producing/composing my ideas"). Results of observations in the art field suggested that the production stage is comprised, in fact, of two stages: a stage that consists of searching for ideas through the creative gesture (sketches, drafts, mock-ups), and then a stage consisting of the realization of an idea that is already constructed (transposing an idea to a concrete medium). The initial stage of "production" describes a similar action, but the underlying cognitive microprocesses are different. In the first case, the goal is to produce in order to formulate an idea whereas in the second case, it is to produce in order to implement an idea that already exists. In a study consisting of interviews of professional artists, Botella et al. (2013) confirmed the stages of first sketches to give a material form to the initial project, testing the forms and ideas that originated from reflection and preliminary 


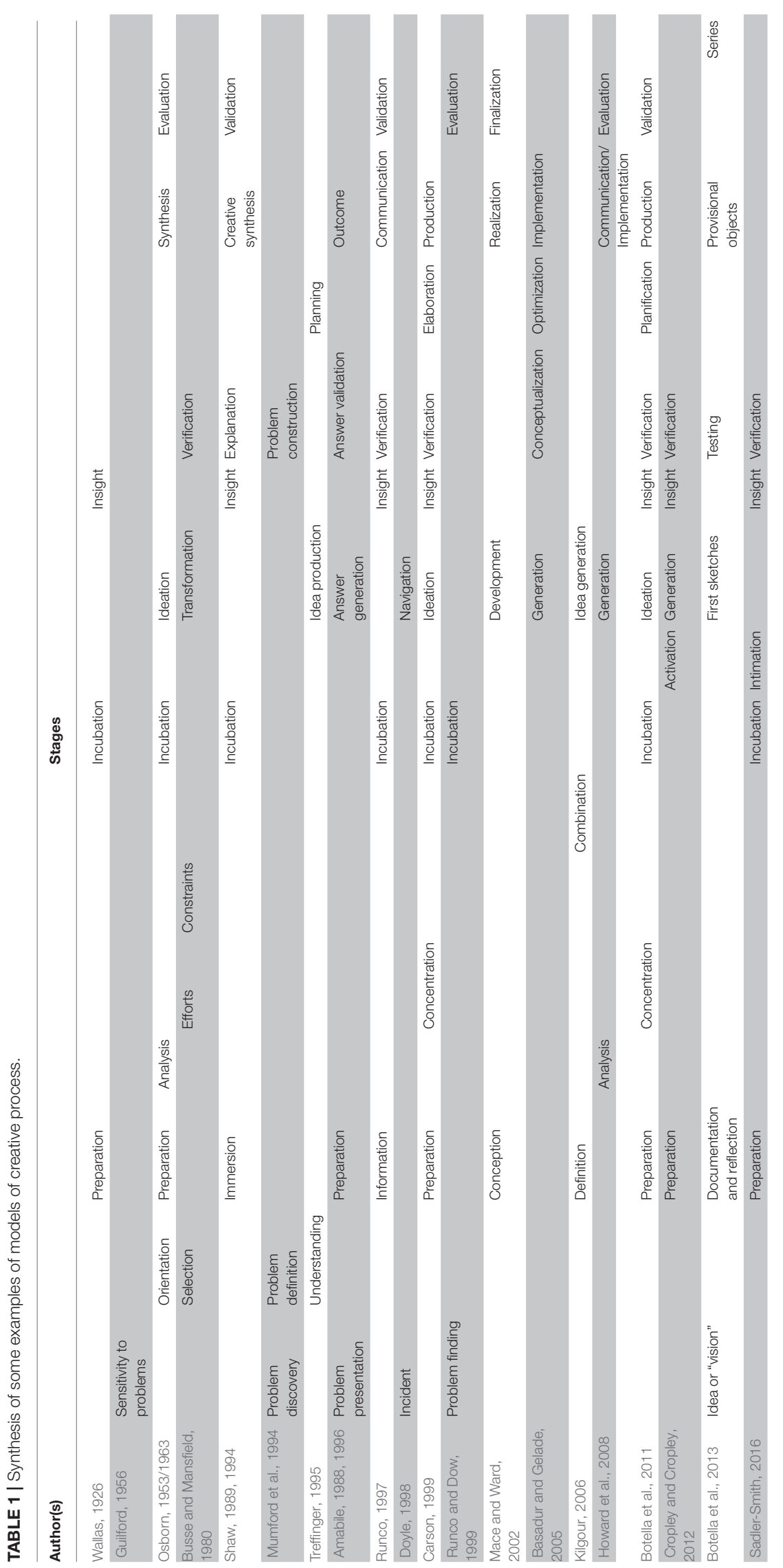


work, and provisional objects, "drafts" and almost-finished products. Revisiting Wallas' model, Cropley and Cropley (2012) mentioned a stage of communication, as Bruford (2015) with musicians.

For Osborn (1953/1963), the last stage is evaluation (Runco and Dow, 1999; or assessment for Bruford, 2015), in which the individual assesses the chosen idea. For Mace and Ward (2002), the final step of the artistic process, called finalization, brings the artistic work to conclusion (or validation according to Botella et al., 2011; Cropley and Cropley, 2012). The artist reassesses the production and may choose to finish, to elaborate, abandon, delay, store, or destroy it. If the artist believes the mission that was set has been accomplished, the artist may choose to exhibit the production. Recently, professional artists suggested to add one more stage with series, transforming a first object to many objects (Botella et al., 2013).

All these models were developed based on rational or empirical approaches. Original works and models from Poincaré and Wallas' were conceived based, respectively, on their own experience and pragmatic empirical observations. Patrick (1935, 1937) supported Wallas proposal by collecting empirical data in terms of observations and verbal reports of poets and artists who were invited to do a specific creative task. Most of the "stage models" are then based on this kind of rational or empirical analyses, with verbalizations, specifications, and clarifications of the processes by the participants themselves in the majority of cases. Therefore, these models maybe be considered as a specific approach to creativity, distinct from the psychometric, problem finding or cognitive experimental approaches (Kozbelt et al., 2010). Recent studies on the four-stages model of Wallas confirmed again that researchers do not agree on the number of stages: Cropley and Cropley (2012) found seven stages whereas Sadler-Smith (2016) found five stages based on Wallas' book.

\section{OBJECTIVES}

Models of the creative process and of the artistic process do not agree on the nature or on the number of steps involved in a creative artistic process (see Howard et al., 2008). This lack of a consensus could be explained by the fact that (a) the creative process is a complex phenomenon as described by Osborn (1953/1963) who believed that creation is set off by "stop-and-go" or "grab what you can"-type processes; (b) models of a creative process are constructed based on a specific creative population and a specific creative domain, though these are described as if they were generic and could apply to all domains whether art, science, music, writing, or design. The process is most often described in general terms, as if it should apply to all creative domains, whether it is art, science, music, writing, or design; (c) descriptions of the artistic process do not always take into account the definition of creativity, in particular the contextually rich, situated nature that originality, and appropriateness may have; and (d) the methodologies used were different [be it a review of the literature (Busse and Mansfield, 1980; Botella et al., 2011), a series of interviews with novelists (Doyle, 1998), with professional artists (Mace and Ward, 2002; Botella et al., 2013), or an applied and consulting-based approach (Carson, 1999)].

The aim of the present study is to question directly some stakeholders of artistic creativity, namely visual art students. However, it is maybe too ambitious to ask them to describe completely their creative process. We suggest that the lack of consensus in the previous studies could be due to the desire to capture all aspects of the creative process in the same study. So, the students interviewed here describe only what constitutes, for them, the stages of their process of artistic creativity. We ask them specifically to list the stages of their process in order to be as exhaustive as possible. This qualitative study makes it possible to identify what stages the students consider relevant in their mental representation of the visual artistic creative process, rather than relying on stages extracted from the scientific literature on creativity. With this study, we will not able to have a macro vision of the entire artistic creative process but we will construct an inventory of the stages involved to picture this process.

Given the descriptive nature of the present research on the artistic creative process, the findings can be integrated in further work as a part of the Creative process Report Diary (CRD, Botella et al., 2017). The CRD is a useful and relevant analytical tool to assess the creative process in a natural context, when it occurs, allowing ecological validity. It is possible to realize various versions of the $\mathrm{CRD}$ depending on the context, the creative field, and any other considerations. The CRD has two parts: a part listing the stages of the creative process (which will be as exhaustive as possible based on the present study) and a part listing factors such as cognitive, conative, emotional, and environmental ones that may come into the creative process (for example, we could assess team work; Peilloux and Botella, 2016). Finally, the CRD allows the creative process to be modeled for individuals in situ during all the time needed for their creation. Thus, the purpose of CRD will be to observe the link and the transitions between the stages of the artistic creative process and to examine which factors will be involved at each stage. However, to do that, we need, in the present study, to list as exhaustively as possible all the stages of the visual artistic creative process which will allow a specific CRD to be created to observe the process in further study.

\section{METHODS}

\section{Participants}

The sample was composed of 28 students in the second year of a visual graphic arts school. Seventeen students were female and 11 were male (mean age $=20.9$ years old, $s d=1.7$, span $=19$ 24 years old). The rational for the choice of this sample was to interview participants with some artistic experience but to avoid a sample habituated to interviews with strongly formatted ideas. In previous research, when we interviewed professional artists (Botella et al., 2013), we noticed some routines in the discourse. Some artists were familiar with interviews and they narrated a story, usually the story of an artwork but sometimes the reports were distanced from their own story and therefore from their own creative process. 


\section{Interview Guide}

The goal of the study was to construct a list of the stages of the process of visual artistic creativity. Given this, the interview guide was purposely kept short and open, and consisted of only two questions: (1) "how does your creative process generally take place?" and (2) "how would you name the stages that you have just mentioned?”

The interviewer's follow-up questions allowed the students to describe another stage of their creative process. The main prompts consisted of reformulating the last sentence provided by the participant and asking "When you did [...], what do you do next?" or "Can you describe more precisely what you do when you finish [...]?" It was very important to not induce ideas with our questions so, we just reformulated the words used by the visual art students themselves to help them list the stages of their artistic creative process.

Interviews were semi-structured and lasted $10 \mathrm{~min}$ on average. Obviously, the interviews were too short to capture all the complexity of the artistic creative process with its "stop-and-go" or "grab what you can" aspects (Osborn, 1953/1963). However, to make an inventory of the stages it was enough. The added value of this study is to focus the interview on the stages that visual art students themselves considered and how they named them.

\section{Procedure}

Ethics approval was not required according to our institution's guidelines and national regulations. After the participants provided informed consent, the volunteer students were interviewed in their art school, during their course on creativity. This situation made it easier for them to recall the stages of their visual artistic creative process. Participants were led to a separate room to take part in a one-on-one discussion with the interviewer. The interviewer (and then, the analyst) was the first author, with knowledge on the literature about creativity and creative process, who had already realized many interviews mainly with artists (Botella et al., 2013; Glaveanu et al., 2013). The prompts consisted of reformulating what participants said to assure that we did not induce the use of certain terms.

\section{RESULTS}

Given our objective was to inventory the stages of the artistic creative process, we analyzed the words employed during the interviews. The terms used by students were grouped in equivalence sets using Tropes software which presents references cited at least three times. The name retained for the category was the most cited term; others citations were used to describe the category. In the first part of the analysis, we focus on the stages of the process of visual artistic creativity that emerged spontaneously from the participants' discourse. Hence, we will deal with the responses to the first question in the interview guide. In the second part, we will examine the stages named by the students. Finally, we will confront these two analyses, in order to check whether the stages named by the participants do indeed correspond to those referenced in the discourse. It is expected that the names will be very similar for both analyses but this confrontation serves to cross-check the categorized sets of terms and their labels.

\section{Identifying the Stages of the Process From the Students' Open Discourse}

Based on the students' responses to the first question in the interview guide, all the terms cited at least three times were listed. It should be noted that the software can already group some terms according to the context: for example, "impossible" and "not possible" are considered as similar. The software can also identify co-occurrences of combined terms, such as "applied art." Then, terms were grouped by the analyst according to the context in which they appeared (see Table 2). The context helped us to identify the terms concerning the creative process. When terms seem to correspond to the same idea, they were grouped together, such as "Sketchpad," "sketch," "drawing," and "writing." We conducted an ascendant hierarchical classification, grouping two by two the closest words. The number of clusters was not decided in advance and the grouping was stopped when we considered that another aggregation was not relevant. Terms that did not refer to the creative process were not retained ("year," "art," "stage," "have an inclination toward," "social environment," etc.).

In Table 2, the number of times that a category was cited and how many students referred to this category are indicated because the same student could mention the same category several times. One stage consists of approaching the subject matter, taking possession of it, gaining knowledge about the subject-related words used (S14: "So, you go there, you throw yourself"). Reflection refers to the students' efforts for deciphering and understanding the topic. This stage may imply visualized images (S1: "I think, I get things straight for a week"). The stage of research involves the student going to the library in order to collect references to artists and to prior work (S4: "I am looking for references to see what has been done. There is a time of documentation"). Then the student constructs a knowledge base of works which have already been produced, before distancing themselves from these works. Inspiration is based on one's impression and experience of a given subject matter (S24: "it's really how I feel it and I know I'll be able to continue on it"). Although the term illumination was not used, we can note the presence of this stage in students' reports of "an idea suddenly appearing" or "coming across an idea by accident" (S6: "It's not totally conscious. It comes like this. Ideas come alone. We feel it. And after that, we try from that to bring this idea in a frame that could be appropriate"). Trials correspond to producing notebooks containing sketches. Students record their sketches, and make attempts before they can find an idea (S27: "I try to explore as many things as possible"). Organization consists of students ordering, guiding, and organizing their approach by mixing existing ideas and combining them together (S25: “There is an order to be defined"). The student will have to select an idea out of all those produced (S25: "I will select what is best"). A work involves inevitably one or more techniques (S18: "Whether computer, photoshop or drawing, rush. Really, exploit everything I know as technical before you get to a final thingy"). Depending 
TABLE 2 | Categories of references used in the students' discourse.

\begin{tabular}{|c|c|c|c|}
\hline Category & No. times cited & Percentage of students (\%) & Other references used \\
\hline Approaching the subject matter & 245 & 100 & Apprehending, starting up, word, concept, project, topic, text, theme \\
\hline Research & 203 & 96.43 & $\begin{array}{l}\text { Artist, basis, library, searching, cinema, knowledge, culture, curiosity } \\
\text { documentation, information, internet, book, research, researching, } \\
\text { reference, providing information }\end{array}$ \\
\hline Trials & 198 & 92.86 & Sketchpad, sketch, drawing, writing, trying, mock-up, note, taking notes \\
\hline Finalization & 119 & 85.17 & $\begin{array}{l}\text { Stopping, end, final, finalizing, adding, resuming, correcting, reworking, } \\
\text { finishing }\end{array}$ \\
\hline Specification & 80 & 85.71 & $\begin{array}{l}\text { Improving, moving forward, changing, continuing, adding depth, detailing, } \\
\text { developing, evolving, perfectionism, photoshop, pushing forward, specifying }\end{array}$ \\
\hline Realization & 98 & 75 & $\begin{array}{l}\text { Composition, make concrete, illustration, implementation, practice, } \\
\text { production, clean, production, product, volume }\end{array}$ \\
\hline Technique & 85 & 71.43 & $\begin{array}{l}\text { Code, color, materials, matter, means, painting, photography, style, } \\
\text { technique, line, typography, use }\end{array}$ \\
\hline Inspiration & 51 & 64.29 & Impression, inspiration, inspire, feeling \\
\hline Reflection & 46 & 57.14 & $\begin{array}{l}\text { Understanding, deciphering, exploiting, reflecting, reflection, vision, } \\
\text { visualization }\end{array}$ \\
\hline Organization & 38 & 46.43 & $\begin{array}{l}\text { Training, link, linking, logic, mixing, order, organizing, steering, connection, } \\
\text { relationship }\end{array}$ \\
\hline Illumination & 37 & 46.43 & Coming across an idea \\
\hline Presentation & 22 & 42.86 & Showing, presentation, handing in \\
\hline Selection & 32 & 39.29 & Choosing, choice, selection, selecting \\
\hline Judgment & 19 & 35.71 & Opinion, looking at \\
\hline Failure & 20 & 28.57 & Failure, mistake, throwing away, missing, beginning again, doing over \\
\hline
\end{tabular}

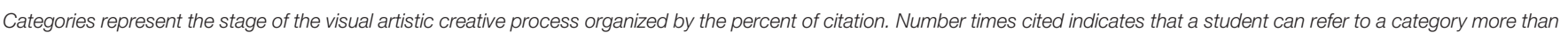
one time. All the others references used to mention a stage are reported in this table.

on individual preferences and on the constraints of the situation, the student will choose to use a particular technique. The product of the creative process is made concrete during the stage of realization (S9: "I go directly to the realization with the materials. I take the painting and I do it directly to clean"). The stage of specification indicates that the student improves, specifies and adds the finishing touches to the work (S15: "I am improving what I have already drawn. Above all, I simplify. Because I tend to put too much"). Finalization refers to the stage in which the work is completed, finished, and voluntarily stopped (S28: "I am very meticulous and I spend a lot of time on the end"). The stage of judgment corresponds to assessing the work that has been produced (S27: "Generally, I have to finish in advance so I can look at it for a long time and then see if something is missing or not. Because sometimes, I have the impression that it is not finished at all and, by dint of looking at it, finally I realize that it misses nothing or that it misses things precisely"). The presentation is the moment when students present their work to their teachers (S20: "It's when I show to the teachers"). The stage of failure indicates that the student has abandoned something, be it the work or an idea. In the latter case, the student throws away one idea and starts something new, or starts again based on an existing work (S3: "If it's not good, I do not leave, I start again. It happens to me often when I'm done and it's ugly, that I know it's not good, I don't care, I spend another 8 hours, 10 hours to rework another volume. In general, when I resume it's still the same theme, but it's not the same idea").

\section{Identifying the Stages of the Process Named by Students}

This analysis focused on the second question in the interview guide, i.e., how the students named the stages in their visual artistic creative process. Terms were grouped in Table 3. From there, we were able to identify 16 stages in the process of visual artistic creativity.

Immersion refers to assimilating the work to be done; it involves listening to the instructions given by the teacher, defining the words in the topic, and entering into the project. Reflection relates to a form of brainstorming where the student attempts to understand, to decipher the topic and to reflect upon it. Research may focus on artists, documents, books, the Internet, and aims for the students to construct a knowledge base for themselves. Inspiration seems to be related to intuition and instinct. Apparition refers to ideas being found and appearing of their own accord. Trials designate all the try-outs, notes, sketches, notes, and testing made by the students. Assembly refers both to attempting a new approach and to the different ideas that emerge from assembling ideas together. The stage of new ideas includes different ideas which emerge. The stage of selection involves choosing an idea. Materials were also mentioned in terms of photography and volume. The stage of realization refers to action, composition, concretization, production, and to the transfer of an idea to a medium. The stage of specification can be viewed as increasing the depth of analysis, developing the work, and correcting it. Finalization is the completion of the work. The 
TABLE 3 | Categories used in naming the stages of the creative process.

\begin{tabular}{|c|c|c|c|}
\hline Category & No. times cited & Percentage of students (\%) & Other references used \\
\hline Research & 58 & 78.57 & $\begin{array}{l}\text { Artist, searching, knowledge, document, information, internet, book, research, researching, } \\
\text { reference }\end{array}$ \\
\hline Trials & 36 & 64.29 & Try-outs, drafts, notebook, croquis, sketch, trial, trying, notes, testing \\
\hline Realization & 27 & 64.29 & $\begin{array}{l}\text { Act, action, application, composition, concretization, illustration, implementation, cleaning up, } \\
\text { production, transcription, transposition }\end{array}$ \\
\hline Selection & 12 & 42.86 & Choice, selection \\
\hline Finalization & 12 & 35.71 & Ending, stopping, final, finalization, finalizing, finishing, finishing touches, corrections \\
\hline Reflection & 14 & 32.14 & Brainstorming, understanding, deciphering, reflection, reflecting \\
\hline Immersion & 10 & 32.14 & Assimilation, definition, defining, listening, immersion, impregnation, reception, entering \\
\hline Specification & 10 & 28.57 & Detailing, detail, developing, development, specification \\
\hline Assembly & 9 & 28.57 & Assembly, assembling, setting up ideas \\
\hline Presentation & 7 & 21.43 & Explaining, justifying, speaking, presentation, hand-in \\
\hline Materials & 7 & 17.86 & Photo, volume, materials \\
\hline Examination & 5 & 17.86 & Taking a step back, examining, questioning \\
\hline Settling & 6 & 14.29 & Decanting, digesting, letting time pass, taking a break \\
\hline Teacher & 6 & 14.29 & Teacher \\
\hline Inspiration & 4 & 14.29 & Inspiration, instinct, intuition \\
\hline Apparition & 6 & 10.71 & Apparition, finding, coming \\
\hline New idea & 3 & 10.71 & New, different ideas, differentiation \\
\hline
\end{tabular}

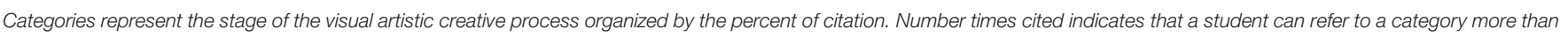
one time. All the others references used to mention a stage are reported in this table.

stage of examination indicates taking a step back from the work, formulating an analysis of the work, and questioning one's own work. Presentation refers to the fact that students must justify, explain, and present their work. The fact that students let the work settle, digest and breathe may refer to the concepts of breaks and incubation. Finally, the teacher was also cited as a part of the stages of the process of artistic creativity when students ask for help because they are stuck or when they need reference.

\section{Confronting the two Analyses and Identifying the Stages in the Process of Visual Artistic Creativity}

This confrontation allowed us to verify that the students had indeed described all the stages in their creative process, thus validating the number and nature of steps involved in the process to integrate these in the CRD (see Table 4). Fourteen stages appear both in the free discourse and the stages named by the students, one stage was mentioned only in the discourse, and two stages were mentioned when naming the stages of the process. In the end, 17 different stages were retained. Only the stage referring to teacher was not retained because the teacher corresponds more to a social support than a stage of the process. Additionally, the teacher can be partially included in the stage of research as a source of knowledge.

In the stage of immersion, the goal is to apprehend the topic at hand and to listen to the instructions given by the teacher. Some students may sometimes feel the need to define the words and concepts present in the topic (S1: "What I do personally, I take the words and I take a few days or even a week depending on the time of the project to get things straight, think about it because sometimes there are topics that are very vague like that and we understand not at all. And then it gets more and more precise."). Such an approach allows them to "soak up" the topic and jump into the fray and start themselves off (S18: "The thing is, I often tend to get into an idea. When you give me a subject or what. I guess right now the thing and what I could do with it."). Reflection makes it possible to understand what should be done, and to decipher the teacher's requirements. Mental work may sometimes begin with visualizing an image. This image may guide the student throughout the process (S20: "Me, I cannot start looking for a word if I do not visualize the final "what." Even if I will redo after...”). During the stage of research the students learn to search for artists, references, documents, and work already produced about the topic that they are apprehending. A solid knowledge base and a culture regarding prior work might help create new and original ideas (S15: "The teachers give us research. Because when we come here, we do not necessarily have a culture in terms of graphics, anyway. They give us references to go see. This is because, often, it is sometimes references of choreographers and it goes a little beyond the field of visual arts and graphics. And suddenly, it allows to compare universes. And then we improve what we do."). Inspiration occurs when an idea emerges slowly and gradually. According to the students, it is based on instinct, impressions, and feelings (S14: "Sometimes you feel that you have a lot of data and from that, you can start to grab something"). Although the word illumination was never mentioned, the literature places a strong emphasis on this stage. It is translated in the interviews as "apparition," "coming across an idea," and "hey, there's an idea!," where the idea sometimes comes from an unknown place (S5: "Sometimes it comes alone."; 
TABLE 4 | Confrontation between the two analyses.

\begin{abstract}
Analysis of the discourse
Apprehending the subject matter:

Apprehending, starting up, word, concept, project, topic, text, theme

Reflection: Understanding, deciphering, exploiting, reflecting, reflection, vision, visualization

Research: Artist, basis, library, searching, cinema, knowledge, culture, curiosity documentation, information, internet, book, research, researching, reference, providing information

Inspiration: Impression, inspiration, inspire, feeling

Illumination: Coming across an idea, coming
\end{abstract}

Trials: Sketchpad, sketch, drawing, writing, trying, mock-up, grading, grade

Organization: Training, link, linking, logic, mixing, order, organizing, steering, connection, relationship

Selection: Choosing, choice, selection, selecting

Technique: Code, color, materials, matter, means, painting, photography, style, technique, line, typography, use

Realization: Composition, make concrete, illustration, implementation, practice, production, clean, product, volume

Specification: Improving, moving forward, changing, continuing, adding depth, detailing, developing, evolving, perfectionism, photoshop, pushing forward, specifying

Finalization: Stopping, end, final, finalizing, adding, resuming, correcting, reworking, finishing

Judgment: Opinion, looking at

Presentation: Showing, presentation, handing in

Failure: Failure, mistake, throwing away, missing, beginning again, doing over
Analysis of the stages named

Immersion: Assimilation, definition, defining, listening, immersion, impregnation, reception, entering

Reflection: Brainstorming, understanding, deciphering, reflection, reflecting

Research: Artist, searching, knowledge, document, information, internet, book, research, researching, reference

Inspiration: Inspiration, instinct, intuition Apparition: Apparition, finding, coming

Trials: Try-outs, drafts, notebook, croquis, sketch, trial, trying, notes, testing

Assembly: Assembly, assembling, setting up ideas

New idea: New, different ideas, differentiation

Selection: Choice, selection

Materials: Photography, volume, materials

Realization: Act, action, application, composition, concretization, illustration, implementation, cleaning up, production, transcription, transposition

Specification: Detailing, detail, developing, development, specification

Finalization: Ending, stopping, final, finalization, finalizing, finishing, finishing touches, corrections

Examination: Taking a step back, examining, questioning

Presentation: Explaining, justifying, speaking, presentation, hand-in

Settling: Decanting, digesting, letting time pass, taking a break
Stages retained

Immersion: Impregnating oneself with the topic, defining the topic, listening to instructions

Reflection: Brainstorming, understanding, visualizing

Research: Searching for references, documents, artists, information

Inspiration: An idea gradually formed, instinct Illumination: "Aha, there's an idea!," emergence of an idea

Trials: Sketches, note-taking, testing, trying out

Assembly: Mixing or assembling ideas together

Ideation: Finding and exploring new ideas

Selection: Choosing ideas

Technique: Choosing a technique, a style, a typography

Realization: Production, composition, concretization, cleaning up

Specification: Refining and detailing

Finalization: Adding finishing touches, correcting, ending

Examination: Taking a step back and examining one's production

Presentation: Explaining and justifying one's production

Break: Letting everything rest, digesting, decanting

Abandoning: Putting aside or abandoning an idea
S21: "I did not look. It fell on me in fact. And so after, you have to bounce back."). The use of notebooks gather the students' trials, their sketches and their notes. They allow the students to try out and test an image. More importantly, the teachers examine the notebooks to follow the evolution of the students' work. Notebooks show students' train of thought, how they achieved a particular work (S2: "These ideas, I always put them in my notebook to show them to the teacher."). Assemblies of ideas are the result of logical connections that the student establishes between several existing ideas. Thus, it corresponds to the direction which the student wishes to give to the production and future work (S3: "I try to mix everything together"). The stage of ideation was not mentioned in the discourse. It was only mentioned when students were naming the stages. Selection refers to classifying and sorting ideas. The goal here is to choose which ideas can be exploited, and which, on the other hand, should be set aside (S24: "It's hard to choose, on which track to go"). Technique is a very important aspect for aspiring artists. They must comply with codes, rules, find a typography, a style of their own. Although this stage was rarely named as such by the students, it is very present in their discourse (S27: "I put in some technique. For example, I had been taught a little about the technique of collage, I had exploited this thing after because I liked it. I tried to distort it from school in my own way."). Realization refers to translating an idea into an image. It is at this point that the composition and production of a material work take shape (S18: "I try to realize it at best"). The stage of specification reveals the improvements, the added details, the changes, and corrections made to the work underway. At this point, students add details that they had not necessarily planned initially (S23: "When I have something that I like, I dig it even more to see if I can exploit it"). Finalization refers to the point at which the student decides that the work is done. The work is complete, or almost at the point of completion (S17: "It's never 
finished. For renderings, there is a fixed date and there it is finished. But just for a grade. But in general, we always have stuff to add, photos to resume, stuff to put back. Generally, we do it if we have a jury at the end of the year. And here, we try to finalize the project of the beginning of the year."). The term judgment was not explicitly mentioned either. However, it can be found in the terms of taking a step back, questioning one's work, observing it with great attention, and thus assessing it (S3: "I look at [my work]. I think instead of teachers. If I was a teacher, if I look at, if there is something wrong, if there is a stain, if I see that there is something wrong, if it is not good, well cut, I'll start all over again."). Although this stage was not directly mentioned in the students' discourse, the stage of the break also seems to exist. Its goal is to let the ideas rest, digest, settle and "breathe." The discourse suggests also the presence of trial and error. Because the word "failure" seems a little strong, we retain the term of "abandoning," whose connotations are less negative (S3: "Sometimes I change my idea and sometimes, when I work, it's not possible like that").

\section{DISCUSSION}

The goals of this study were to determine the nature and number of stages present in the creative visual artistic process in order to build a specific CRD. Twenty-eight art students were asked to describe their process of visual artistic creativity and to name its stages. By comparing the discourse of these art students and the names they gave to the various stages of their work, we identified 17 stages.

Immersion is present in several existing models. It corresponds to preparation in Wallas' (1926) model (see Table 5 for a synthesis). Wallas views preparation as a preliminary analysis which makes it possible to define and set the problem. The same idea is present in Carson's (1999) consulting-centric model and in the work on the creative process of actors (Blunt, 1966; Nemiro, $1997,1999)$. Osborn $(1953 / 1963)$ speaks instead of orientation, in which the individual identifies the problem that is to be solved. Shaw $(1989,1994)$ proposes also the term "immersion." Reflection is typically included in preparation. Osborn proposes a stage when the individual takes a step back to examine the connections that exist between different ideas. More recently, this stage of reflection was identified in interviews with professional artists (Botella et al., 2013). The stage of research is required by the school of art (S8: "We have a lot of instructions from the teachers who help us. We must go through research."). Research is also generally included in preparation. It should be noted that in Treffinger's model (Treffinger, 1995), preparation is called understanding. The goal here is for the individual to search for information regarding the problem at hand. Also, Runco (1997) mentions a stage of information. Here, the research stage could help visual art students to differentiate their own work from previous ones (Bruford, 2015). In the interviews with professional artists (Botella et al., 2013), this search stage was coupled with reflection, as a search for means (i.e., material or technological) to transform the initial idea into a real production.

Inspiration corresponds to intuition and metacognition (Cropley, 1999). Amongst other things, it allows us to identify which approach will be more efficient than another. Policastro
TABLE 5 | Correspondence between the stages retained in the present study and the existing stages in research field.

\begin{tabular}{|c|c|}
\hline $\begin{array}{l}\text { Stages retained in } \\
\text { the present study }\end{array}$ & Correspondence with existing stages \\
\hline Immersion & $\begin{array}{l}\text { Preparation (Wallas, 1926; Osborn, 1953/1963; Blunt, } \\
\text { 1966; Amabile, 1988; Nemiro, 1997, 1999; Carson, } \\
\text { 1999; Botella et al., 2011) } \\
\text { Sensitivity to problems (Guilford, 1956) } \\
\text { Orientation (Osborn, 1953/1963) } \\
\text { Immersion (Shaw, 1989, 1994) } \\
\text { Problem discovery (Mumford et al., 1994) } \\
\text { Problem presentation (Amabile, 1988) } \\
\text { Problem finding (Runco and Dow, 1999) } \\
\text { Conception (Mace and Ward, 2002) } \\
\text { Definition (Kilgour, 2006) }\end{array}$ \\
\hline Reflection & $\begin{array}{l}\text { Preparation (Wallas, 1926; Osborn, 1953/1963; Blunt, } \\
\text { 1966; Amabile, 1988; Nemiro, 1997, 1999; Carson, } \\
\text { 1999; Botella et al., 2011) } \\
\text { Analysis (Osborn, 1953/1963; Howard et al., 2008) } \\
\text { Efforts (Busse and Mansfield, 1980) } \\
\text { Problem definition (Mumford et al., 1994) } \\
\text { Conception (Mace and Ward, 2002) } \\
\text { Generation (Basadur and Gelade, 2005; Howard et al., } \\
\text { 2008) } \\
\text { Goal of creation (Fürst et al., 2012) } \\
\text { Documentation and reflection (Botella et al., 2013) }\end{array}$ \\
\hline Research & $\begin{array}{l}\text { Preparation (Wallas, 1926; Osborn, 1953/1963; Blunt, } \\
\text { 1966; Amabile, 1988; Nemiro, 1997, 1999; Carson, } \\
\text { 1999; Botella et al., 2011) } \\
\text { Efforts (Busse and Mansfield, 1980) } \\
\text { Problem definition (Mumford et al., 1994) } \\
\text { Understanding (Treffinger, 1995) } \\
\text { Information (Runco, 1997) } \\
\text { Conception (Mace and Ward, 2002) } \\
\text { Documentation and reflection (Botella et al., 2013) } \\
\text { Differentiation (Bruford, 2015) }\end{array}$ \\
\hline Inspiration & $\begin{array}{l}\text { Intuition and metacognition (Cropley, 1999) } \\
\text { Idea or vision (Botella et al., 2013) } \\
\text { Intimation (Sadler-Smith, 2016) }\end{array}$ \\
\hline Illumination & $\begin{array}{l}\text { Insight (Wallas, 1926; Ghiselin, 1952; Gruber and Davis, } \\
\text { 1988; Weisberg, 1988; Shaw, 1989, 1994; Runco, } \\
\text { 1997; Carson, 1999; Botella et al., 2011) } \\
\text { Idea production (Treffinger, 1995) } \\
\text { Answer generation (Amabile, 1988) } \\
\text { Incident (Doyle, 1998) } \\
\text { Conceptualization (Basadur and Gelade, 2005) }\end{array}$ \\
\hline Trials & $\begin{array}{l}\text { Transformation (Busse and Mansfield, 1980) } \\
\text { Navigation (Doyle, 1998) } \\
\text { Idea development (Mace and Ward, 2002) } \\
\text { First sketches and testing (Botella et al., 2013) }\end{array}$ \\
\hline Assembly & $\begin{array}{l}\text { Divergent thinking (Guilford, 1950) } \\
\text { Combination (Kilgour, 2006) }\end{array}$ \\
\hline Ideation & $\begin{array}{l}\text { Ideation (Osborn, 1953/1963; Carson, 1999; Botella } \\
\text { et al., 2011) } \\
\text { Idea generation (Kilgour, 2006) } \\
\text { Generation (Cropley and Cropley, 2012) }\end{array}$ \\
\hline Selection & $\begin{array}{l}\text { Selection (Busse and Mansfield, 1980; Bruford, 2015) } \\
\text { Concentration (Carson, 1999; Botella et al., 2011) }\end{array}$ \\
\hline Technique & Constraints (Busse and Mansfield, 1980) \\
\hline Specification & $\begin{array}{l}\text { Elaboration (Berger et al., 1957; Carson, 1999) } \\
\text { Explanation (Shaw, 1989, 1994) } \\
\text { Planning (Treffinger, 1995; Botella et al., 2011) } \\
\text { Optimization (Basadur and Gelade, 2005) } \\
\text { Documentation (Botella et al., 2013) }\end{array}$ \\
\hline
\end{tabular}

(Continued) 
TABLE 5 | Continued

\begin{tabular}{|c|c|}
\hline $\begin{array}{l}\text { Stages retained in } \\
\text { the present study }\end{array}$ & Correspondence with existing stages \\
\hline Realization & $\begin{array}{l}\text { Synthesis (Osborn, 1953/1963; Shaw, 1989, 1994) } \\
\text { Problem construction (Mumford et al., 1994) } \\
\text { Production (Treffinger, 1995; Carson, 1999; Botella et al., } \\
\text { 2011) } \\
\text { Realization (Mace and Ward, 2002) } \\
\text { Implementation (Basadur and Gelade, 2005; Howard } \\
\text { et al., 2008) } \\
\text { Provisional objects (Botella et al., 2013) }\end{array}$ \\
\hline Finalization & Finition (Mace and Ward, 2002) \\
\hline Judgement & $\begin{array}{l}\text { Verification (Wallas, 1926; Busse and Mansfield, 1980; } \\
\text { Armbruster, 1989; Runco, 1997; Carson, 1999; Botella } \\
\text { et al., 2011) } \\
\text { Evaluation (Osborn, 1953/1963; Runco and Dow, 1999; } \\
\text { Howard et al., 2008) } \\
\text { Validation (Amabile, 1988; Shaw, 1989, 1994; Runco, } \\
\text { 1997; Botella et al., 2011; Cropley and Cropley, 2012) } \\
\text { Assessment (Bruford, 2015) }\end{array}$ \\
\hline Presentation & $\begin{array}{l}\text { Outcome (Amabile, 1988) Communication (Runco, 1997; } \\
\text { Howard et al., 2008; Cropley and Cropley, 2012) }\end{array}$ \\
\hline Break & $\begin{array}{l}\text { Incubation (Wallas, 1926; Patrick, 1937; Osborn, } \\
\text { 1953/1963; Dreistadt, 1969; Shaw, 1989, 1994; Smith } \\
\text { and Blankenship, 1989, 1991; Smith and Vela, 1991; } \\
\text { Russ, 1993; Runco, 1997; Carson, 1999; Runco and } \\
\text { Dow, 1999; Botella et al., 2011) }\end{array}$ \\
\hline Withdrawal & Abandoning (Mace and Ward, 2002) \\
\hline
\end{tabular}

(1995) defines intuition as an implicit form of information processing, which is intended to anticipate and guide creative research. According to her, intuition may allow an unconscious shift from incubation to illumination. However, intuition was never considered a stage in the creative process or in the artistic process. Therefore, it is a stage that is specific to the current study. As described by the students, the inspiration stage is close to the stage on intimation added between incubation and insight (Sadler-Smith, 2016). It is surprising and interesting that visual art students consider inspiration as a stage of their creative process. So, a replication of this study will be necessary to confirm if it is really a stage or if it is a factor involved in the creative process. The word "illumination" was not mentioned by the students as such. Numerous authors have previously shown that the illumination stage was seldom mentioned by students in art. Doyle (1998) has described illumination as an accident, where the solution emerges in a sudden and unexpected way (Wallas, 1926). Hence, the description that the students made of this stage might be termed illumination: the idea comes or appears in an unexpected manner. Other authors believe that this experience of illumination would, in most cases, be more gradual than sudden (Ghiselin, 1952; Gruber and Davis, 1988; Weisberg, 1988). Although it is possible that illumination is not a part of all creative processes, or that the creators might not always be conscious of it, the stage of illumination remains a key stage in the creative process, because it is at this stage that the idea takes shape.
The trials, tests, and fiddling made by students may correspond to the stage of idea development in Mace and Ward's model (Mace and Ward, 2002). In their description of the artistic process, Mace and Ward argue that, during the development of an idea, the artist will structure, complete, and restructure the idea. Authors indicate that this trial stage will allow artists to form a more precise idea of the initial project for themselves. This stage is worked in Art school with sketchpads.

Assembly corresponds to the microprocess of divergent thinking, in which ideas are assembled and mixed together. In contrast, convergent thinking makes it possible to focus on a single idea (Guilford, 1950). This mode of thinking allows individuals to find the one and only solution to a problem. The generation of ideas that have not yet been checked and assessed corresponds to ideation (Carson, 1999). Osborn (1953/1963) mentions a stage of synthesis, which consists of putting ideas together and distinguishing relations between them.

Selection refers to concentration (Carson, 1999). Concentration makes it possible to focus the attention of the individual on those solutions deemed to be adequate, and to reject other solutions. No model emphasizes the stage of choosing a technique. Yet, the artist must identify the technique that will allow them to make the idea materialize in the best possible way. During the interviews with professional artists, technical issues were included in the stage of documentation (Botella et al., 2013). However, in the present study, because $71.43 \%$ of the students mentioned this stage in their discourse and $17.86 \%$ named it directly, we decided to consider "technique" as a specific stage of the visual artistic creative process. In further studies, it will be interesting to explore if this stage is specific to visual arts or if it is a more common stage concerning other creative domains.

Specification might correspond to elaboration. Berger et al. (1957) defined elaboration as the individual's ability to provide detail to the ideas produced. This stage may also tie in with creative explanation, whose goal is for the artist to explain the ideas (Shaw, 1989, 1994).

Realization refers to the creative production (Treffinger, 1995) or to creative synthesis (Shaw, 1989, 1994). The goal here is to make the idea concrete. "Technique" is generally included in this stage. However, it seems that production points to the act of creating and to the gestures involved rather than to the cognitive or emotional choice of a technique. Mace and Ward (2002) speak also of realization, i.e., the transformation of an idea into a "physical entity." They note that for some physical arts and for a wide variety of artistic media it is necessary to have a detailed idea of what the artist is going to do. Hence, some decisions-such as, for example, those related to the choice of a technique-should be anticipated.

Finalization corresponds, at least in part, to the finition phase in Mace and Ward (2002). The authors argue that finalization implies that the individual has decided that his/her work is finished. If the artist considers the work to be successful and satisfactory and they may choose to exhibit it. In that case, the stage of finalization also includes hanging up or exhibiting the work. 
The stage of judgement of the creative production is very often named in models of the creative process. In particular, Wallas (1926) writes about verification, where the individual assesses the idea that has emerged. At this stage, one must take a step back from one's work and assess it. Verification may be of two kinds: "internal" verification, i.e., a comparison between the idea that has been produced and the idea formed during illumination or "internal" verification, which consists of anticipating the reactions of the audience (Armbruster, 1989). According to Busse and Mansfield (1980), verification may take place earlier during the process, as the individual first verifies the ideas and then elaborates a solution. Other authors have argued that judgment occurs at a later stage. For example, Osborn (1953/1963) considers that evaluation is the moment when the individual evaluates the chosen idea. When describing the creative process, Osborn (1953/1963) mentions the stage of analysis, in which the individual takes a step back to examine the connections that form between ideas and their importance. In contrast, Shaw $(1989,1994)$ addresses the concept of validation, thus emphasizing the importance of this stage. According to him, personal validation consists of appreciating one's own work and in using the experience acquired over the course of this process to generate a new creative process. In addition to personal validation, there exists a collective level of validation. The latter deals with the evaluation of a creative production by peers, by an audience or by a critic. Collective validation can only lead to a new process if there is acceptance of the evaluation that has been formulated. If the production is validated, it can then be followed by a series in which the idea is extended to several works (Botella et al., 2013).

The stage of presentation is not typically described as such in models of the creative process or of the artistic process; its goal is to present the work to teachers. In the case of professional artists, this would refer more to the sale of a work. However, recent models included a communication stage (Runco, 1997; Howard et al., 2008; Cropley and Cropley, 2012).

The term "break" which has emerged in the stages named by students might correspond to incubation. As we have seen, this stage is very difficult to assess and to take into account (Botella et al., 2011), even though it is essential (Patrick, 1937; Dreistadt, 1969; Smith and Blankenship, 1989, 1991; Smith and Vela, 1991), especially to the expression of artistic creativity (Russ, 1993). The words used by the students highlight some unconscious associations. Indeed, they talk about letting their ideas rest, letting them digest and decant. Incubation is always difficult to evaluate, because it relies in most cases on unconscious work. Finally, although the stage of withdrawal is a subject of research, it is not included in most models of the creative process. Only Mace and Ward (2002) take into account a clear possibility of abandoning the process at any time. Even if the process is brutally interrupted, the artist develops continuously new knowledge. This knowledge is the result of a perpetual, dynamic interaction with artistic practice. Artists extend and refine their repertoire of skills, techniques, and knowledge. Also they sharpen their artistic interests and personality. New ideas can emerge in this work, to be reused later.

\section{CONCLUSION}

Although this study was limited by the interview methodand thus focused on students' implicit theories of their own creative process-it allowed us to identify multiple stages in the process of visual artistic creativity. Because of the implicit theories and the number of models suggesting a linear sequence of stages, sometimes with some loops or cycles possible, it seems too ambitious to understand the sequence of the stages from interviews. The present study invites us to rethink what composes an artistic creative process. Even if we already have a long list of models, none is complete and satisfactory. It is possible that we may need to construct and maintain a list of all the stages of the creative process which can then be adapted to each domain, given that the creative process may vary depending upon the area in question (Baer, 1998, 2010; Botella and Lubart, 2015). Given this uncertainty, continued research into the creative process is indicated. For now, the present list of stages of the visual artistic creative process could help teachers in their coursework. During the interviews, students indicated that the stages of research and the use of the diary notebook were required by their art school. This appears as a limitation of the present study. We are not sure if art students described the prescriptive stages in their Art school or their real stages of creation. The question was oriented how their creative process generally takes place but because they are art students and they were interviewed in their art school, some prescriptive stages appears in their discourse. However, during the interviews, some students had specified if the stage is prescriptive and we indicated this point throughout this paper. With the updated list, teachers could propose other exercises to guide art students for all the stages. Moreover, outside an educational context, the demand for consultancy to stimulate business creativity is increasing (see Berman and Korsten, 2010), and the current research may also provide a helpful template for the effective management of creative processes in this area of industrial innovation. However, we have to be careful about the use of such a list. By conceptualizing the creative process, are we actually at risk of creating a "uniform" prescriptive model of how to be creative? We can hypothesize that some creative process are more adapted to some creative individuals but it would be counterproductive to try to force all individuals to engage in the same process. The creative process varies across fields (Botella and Lubart, 2015) and probably also across culture, creators' personalities, and tasks.

These stages and more precisely their sequence should be validated in the field, by observing students as they carry out artistic work-notably to determine the exact succession of the stages-using a tool like the CRD. Moreover, it will be interesting to observe the collaborative creative process as well as to situate the process in a more global socio-cultural approach. As we saw in the introduction, the creative process can be described using micro-level or macro-level approaches and more globally takes place in a particular socio-cultural context. These approaches could be used directly during observations of the creative process and associated with cognitive, conative, emotional, and environmental factors involved in the process. 


\section{ETHICS STATEMENT}

All subjects gave written informed consent in accordance with the Declaration of Helsinki.

\section{REFERENCES}

Amabile, T. M. (1988). A model of creativity and innovation in organizations. Res. Organ. Behav. 10, 123-167.

Amabile, T. M. (1996). Creativity in Context. Boulder, CO: Westview Press.

Arlin, P. K. (1986). "Problem finding and young adult cognition," in Adult Cognitive Development: Methods and Models, eds R. A. Mines and K. S. Kitchener (New York, NY: Praeger), 22-32.

Armbruster, B. B. (1989). "Metacognition in creativity," in Handbook of Creativity, eds E. P. Torrance, J. A. Glover, R. R. Ronning and C. R. Reynolds (New York, NY: Plenum), 177-182. doi: 10.1007/978-1-4757-5356-1_10

Baer, J. (1998). The case for domain specificity of creativity. Creat. Res. J. 11, 173-177. doi: 10.1207/s15326934crj1102_7

Baer, J. (2010). "Is creativity domain specific?" in The Cambridge Handbook of Creativity, eds J. C. Kaufman and R. J. Sternberg (Cambridge: Cambridge University Press), 321-341. doi: 10.1017/CBO9780511763205.021

Basadur, M., and Gelade, G. A. (2005). Modelling applied creativity as a cognitive process: theoretical foundations. Kor. J. Think. Prob. Solving 15, 13-41.

Berger, R. M., Guilford, J. P., and Christensen, P. R. (1957). A factor-analytic study of planning abilities. Psychol. Monogr. 71, 1-29. doi: 10.1037/h00 93704

Berman, S., and Korsten, P. (2010). Capitalizing on Complexity: Insights from the Global Chief Executive Officer Study. Somers, NY: IBM.

Blunt, J. (1966). The Composite Art of Acting. New York, NY: Macmillan.

Boden, M. A. (2004). The Creative Mind: Myths and Mechanisms. Abingdon: Routledge. doi: 10.4324/9780203508527

Botella, M., Glaveanu, V. P., Zenasni, F., Storme, M., Myszkowski, N., Wolff, M., et al. (2013). How artists create: creative process and multivariate factors. Learn. Individ. Diff. 26, 161-170. doi: 10.1016/j.lindif.2013.02.008

Botella, M., and Lubart, T. (2015). "Creative processes: art, design and science," in Multidisciplinary Contributions to the Science of Creative Thinking, eds G. E. Corazza and S. Agnoli (Singapour: Springer), 53-65.

Botella, M., Nelson, J., and Zenasni, F. (2016). "Les macro et micro processus créatifs [The macro and micro creative processes]," in Créativité et apprentissage [Creativity and learning], ed I. Capron-Puozzo (Louvain-la-Neuve: De Boeck), 33-46.

Botella, M., Nelson, J., and Zenasni, F. (2017). It is time to observe the creative process: how to use a creative process Report Diary (CRD). J. Creat. Behav. doi: $10.1002 /$ jocb. 172

Botella, M., Zenasni, F., and Lubart, T. I. (2011). A dynamic and ecological approach to the artistic creative process in arts students: an empirical contribution. Empir. Stud. Arts 29, 17-38. doi: 10.2190/EM.29.1.b

Bruford, W. (2015). Making it Work: Creative Music Performance and the Western Kit Drummer, Unpublished dissertation, University of Surrey.

Burnard, P. (2012). Musical Creativities in Practice. Oxford: Oxford University Press. doi: 10.1093/acprof:oso/9780199583942.001.0001

Busse, T. V., and Mansfield, R. S. (1980). Theories of the creative process: a review and a perspective. J. Creat. Behav. 14, 91-132. doi: 10.1002/j.2162-6057.1980.tb00232.x

Carson, D. K. (1999). “Counseling," in Encyclopedia of Creativity, Vol. 1, eds M. A. Runco and S. R. Pritzker (New York, NY: Academic Press), 395-402.

Cropley, A. J. (1999). "Definitions of creativity," in Encyclopedia of Creativity, Vol. 1, eds M. A. Runco and S. R. Pritzker (New York, NY: Academic Press), 511-524.

Cropley, D. H., and Cropley, A. J. (2012). A psychological taxonomy of organizational innovation: resolving the paradoxes. Creat. Res. J. 24, 29-40. doi: 10.1080/10400419.2012.649234

Dewey, J. (1934). Art as Experience. New York, NY: Penguin Books.

Doyle, C. L. (1998). The writer tells: the creative process in the writing of literacy fiction. Creat. Res. J. 11, 29-37. doi: 10.1207/s15326934crj1101_4

\section{AUTHOR CONTRIBUTIONS}

MB methodology, interviews, analyses, and writing; FZ methodology and writing; and TL methodology and writing.

Dreistadt, R. (1969). The use of analogies and incubation in obtaining insights in creative problem solving. J. Psychol. 71, 159-175. doi: 10.1080/00223980.1969.10543082

Fürst, G., Ghisletta, P., and Lubart, T. (2012). The creative process in visual art: a longitudinal multivariate study. Creat. Res. J. 24, 283-295. doi: 10.1080/10400419.2012.729999

Getzels, J. W., and Csikszentmihalyi, M. (1976). "Concern for discovery in the creative process," in The Creativity Question, eds A. Rothenberg and C. R. Hausman (Durham, NC: Duke University Press), 161-165.

Ghiselin, B. (1952). The Creative Process. Berkeley, CA: University of California Press.

Glăveanu, V. P. (2010). Paradigms in the study of creativity: introducing the perspective of cultural psychology. New Ideas Psychol. 28, 79-93. doi: 10.1016/j.newideapsych.2009.07.007

Glaveanu, V. P., Lubart, T., Bonnardel, N., Botella, M., De Biasi, P.-M., De Sainte Catherine, M., et al. (2013). Creativity as action: findings from five creative domains. Front. Educ. Psychol. 4:176. doi: 10.3389/fpsyg.2013. 00176

Gruber, H. E. (1989). “The evolving systems approach to creative work," in Creative People at Work: Twelve Cognitive Case Studies, eds D. B. Wallace and H. E. Gruber (New York, NY: Oxford University Press), 3-24.

Gruber, H. E., and Davis, S. N. (1988). "Inching our way up Mount Olympus: the evolving systems approach to creative thinking," in The Nature of Creativity, ed R. J. Sternberg (New York, NY: Cambridge University Press), 243-270.

Guilford, J. P. (1950). Creativity. Am. Psychol. 5, 444-454. doi: 10.1037/h0063487

Guilford, J. P. (1956). Structure of intellect. Psychol. Bull. 53, 267-293. doi: $10.1037 / \mathrm{h} 0040755$

Howard, T. J., Culley, S. J., and Dekoninck, E. (2008). Describing the creative design process by the integration of engineering design and cognitive psychology literature. Des. Stud. 29, 160-180. doi: 10.1016/j.destud.2008.01.001

Kilgour, M. (2006). Improving the creative process: analysis of the effects of divergent thinking techniques and domain specific knowledge on creativity. Int. J. Business Soc. 7, 79-107.

Kozbelt, A., Beghetto, R. A., and Runco, M. A. (2010). "Theories of creativity," in The Cambridge Handbook of Creativity, Vol. 2, eds J. C. Kaufman and R. J. Sternberg (New York, NY: Cambridge University Press), 20-47.

Lubart, T. I. (2001). Models of the creative process: past, present and future. Creat. Res. J. 13, 295-308.

Lubart, T. I., Mouchiroud, C., Tordjman, S., and Zenasni, F. (2015). Psychologie de la Créativité (Deuxième Edition) [Psychology of Creativity]. Paris: Armand Colin.

Mace, M.-A., and Ward, T. (2002). Modeling the creative process: a grounded theory analysis of creativity in the domain of art making. Creat. Res. J. 14, 179-192. doi: 10.1207/S15326934CRJ1402_5

Mumford, M. D., Reiter-Palmon, R., and Redmond, M. R. (1994). "Problem construction and cognition: applying problem representations in ill-defined domains," in Problem Finding, Problem Solving, and Creativity, ed M. A. Runco (Norwood, NJ: Ablex), 3-39.

Nemiro, J. (1997). Interpretative artists: a qualitative exploration of creative process of actors. Creat. Res. J. 10, 229-239.

Nemiro, J. (1999). “Acting," in Encyclopaedia of Creativity, Vol. 1, eds M. A. Runco and S. R. Pritzker (New York, NY: Academic Press), 1-8.

Osborn, A. F. (1953/1963). Applied Imagination, 3rd Edn. New York, NY: Scribners.

Patrick, C. (1935). Creative thought in poets. Arch. Psychol. 178, 1-74.

Patrick, C. (1937). Creative thought in artists. J. Psychol. 4, 35-73. doi: 10.1080/00223980.1937.9917525

Peilloux, A., and Botella, M. (2016). Ecological and dynamical study of the creative process and affects of scientific students working in groups. Creat. Res. J. 28, 165-170. doi: 10.1080/10400419.2016.1162549 
Policastro, E. (1995). Creative intuition: an integrative review. Creat. Res. J. 8, 99-113. doi: 10.1207/s15326934crj0802_1

Runco, M. A. (1997). The Creativity Research Handbook. Cresskill, NJ: Hampton Press.

Runco, M. A., and Dow, G. (1999). "Problem finding," in Encyclopedia of Creativity, Vol. 2, eds M. A. Runco and S. R. Pritzker (New York, NY: Academic Press), 433-435.

Russ, S. W. (1993). Affect and Creativity: The Role of Affect and Play in the Creative Process. Hillsdale, NJ: Lawrence Erlbaum Associates Inc.

Sadler-Smith, E. (2016). Wallas' four-stage model of the creative process : more than meets the eye ? Creat. Res. J. 27, 342-352. doi: 10.1080/10400419.2015.1087277

Schlewitt-Haynes, L. D., Earthman, M. S., and Burns, B. (2002). Seeing the world differently: an analysis of descriptions of visual experiences provided by visual artists and nonartists. Creat. Res. J. 14, 361-372. doi: 10.1207/S15326934CRJ1434_7

Shaw, M. P. (1989). The eureka process: a structure for the creative experience in science and engineering. Creat. Res. J. 2, 286-298. doi: $10.1080 / 10400418909534325$

Shaw, M. P. (1994). "Affective components of scientific creativity," in Creativity and Affect, eds M. P. Shaw and M. A. Runco (Westport: Ablex Publishing), 3-43.

Smith, S. M., and Blankenship, S. E. (1989). Incubation effects. Bull. Psychon. Soc. 27, 311-314. doi: 10.3758/BF03334612

Smith, S. M., and Blankenship, S. E. (1991). Incubation and the persistence of fixation in problem solving. Am. J. Psychol. 104, 61-87. doi: 10.2307/1422851

Smith, S. M., and Vela, E. (1991). Incubated reminiscence effects. Mem. Cogn. 19, 168-176. doi: 10.3758/BF03197114
Stanko-Kaczmarek, M. (2012). The effect of intrinsic motivation on the affect and evaluation of the creative process among fine arts students. Creat. Res. J. 24, 304-310. doi: 10.1080/10400419.2012.730003

Torrance, E. P. (1962). Guiding Creative Talent. Englewood Cliffs, NJ: PrenticeHall. doi: 10.1037/13134-000

Treffinger, D. J. (1995). Creative problem solving: overview and educational implications. Educ. Psychol. Rev. 7, 301-312. doi: 10.1007/BF02213375

Wallas, G. (1926). The Art of Thought. New York, NY: Harcourt, Brace and Company.

Weisberg, R. W. (1988). "Problem solving and creativity", in The Nature of Creativity: Contemporary Psychological Perspectives, ed R. J. Sternberg (Cambridge: Cambridge University Press), $148-176$.

Yokochi, S., and Okada, T. (2005). Creative cognitive process of art making: a field study of a traditional Chinese ink painter. Creat. Res. J. 17, 241-255.

Conflict of Interest Statement: The authors declare that the research was conducted in the absence of any commercial or financial relationships that could be construed as a potential conflict of interest.

Copyright (c) 2018 Botella, Zenasni and Lubart. This is an open-access article distributed under the terms of the Creative Commons Attribution License (CC BY). The use, distribution or reproduction in other forums is permitted, provided the original author(s) and the copyright owner(s) are credited and that the original publication in this journal is cited, in accordance with accepted academic practice. No use, distribution or reproduction is permitted which does not comply with these terms. 